\title{
RELIABILITY AND VALIDITY OF THE CHINESE DEPRESSION ADJECTIVE CHECK LISTS ${ }^{1}$
}

CATHY RUEY LING CHU

National Taiwan University Taipei. Taiwan
BERNARD LUBIN ${ }^{2}$

University of Missouriat Kansas City
STANLEY SUE

University of California at Los Angeles

Presented data on the translation and on the reliability and concurrent validity of the Chinese version of the Depression Adjective Check Lists (DACL). Reliability and validity coefficients are significant and of sufficient magnitude to warrant their use in research $(N=37)$.

The Depression Adjective Check Lists (DACL) (Lubin, 1981) are brief selfadministered measures of state depression with equivalent forms (Lubin, Caplan, \& Collins, 1980; Lubin, Dupre, \& Lubin, 1967). They have been used in a wide variety of experimental, clinical, and epidemiological studies. National norms also are available (Levitt, Lubin, \& Brooks, 1983; Lubin, 1981). The DACL is being translated into several languages in order to provide an instrument for cross-cultural and cross-ethnic research. Studies of the reliability and validity of the Spanish DACL (Lubin, Millham, \& Paredes, 1980; Lubin, Schoenfeld, Rinck, \& Millham, 1980) and of the Hebrew DACL (Lomranz, Lubin, Eyal, \& Medini, 1981) have been completed.

The purpose of this article is to present preliminary information on the reliability and validity of the Chinese translation of the DACL.

\section{METHOD}

\section{Translation}

Translations were made by five bilingual psychological counselors who worked independently and then met to discuss discrepant items. A consensus then was achieved on these items. Two additional bilingual psychologists received the English and Chinese versions and were asked to rate each adjective for adequacy of translation on a 3-point scale, "not good," "good," and "very good." Only one judge rated any of the 102 adjectives (5) on lists E, F, and G as "not good," but he could not suggest alternatives. The other judges rated all translated adjectives as either "good" or "very good."

The Chinese DACLs together with Chinese versions of the Bradburn Scale (Bradburn, 1969), the Katz Social Adjustment Scale (Symptom Subscale) (Katz \& Lyerly, 1963), the Self-anchoring Striving Scale (Cantril, 1969), the Ko Mental Health Questionnaire (Ko, 1972), and a 7-point self-rating scale of depressed affect were administered to a freshman class at Fu Jen Catholic University (males $=624$; females $=$ 683).

\section{RESULTS AND DISCUSSION}

\section{Adequacy of Translation}

A group of bilingual $S$ s $(N=21)$ received lists $\mathrm{E}, \mathrm{F}$, and $\mathrm{G}$, on which adjectives 1 through 17 (left column) were printed in Chinese and adjectives 18 through 34 (right column) were printed in English. The order of translated adjectives was counter-balanced for another group of $S \mathrm{~s}(N=16)$.

No significant order effect was found whether the Chinese adjectives occurred in the left- or right-hand column. When adjectives 1 through 17 were printed in Chinese, the

${ }^{1}$ Presented at the annual meeting of the American Psychological Association, Washington, August 1982.

${ }^{2}$ Reprint requests should be sent to Bernard Lubin, Department of Psychology, University of Missouri at Kansas City, 5305 Holmes, Kansas City, Missouri 64110. 
correlations between the Chinese and English half lists were: $\mathrm{E}=.76(p<.001), \mathrm{F}=.82$ $(p<.001)$, and $\mathrm{G}=.80(p<.001)$; when adjectives 1 through 17 were printed in English, the correlations were: $\mathrm{E}=.85(p<.001), \mathrm{F}=.78(p<.001)$, and $\mathrm{G}=.78(p<.001)$. These correlations are of a high order and are almost identical to the split-half reliabilities for the Chinese forms to be presented below and to the split-half reliabilities for the English forms $(E=.85 ; F=.85$, and $G=.89)$ (Lubin \& Himelstein, 1976). Additional evidence of the fidelity of the translations is provided by the fact that $t$-tests between scores on the Chinese and English half lists taken by bilingual $S$ s in the same session are nonsignificant.

\section{Reliability}

Table 1 presents the split-half, alternate form, and test-retest reliabilities for both sexes combined for the Chinese and English versions of the DACL. All correlations are significant at well beyond the .01 level. It is interesting that these reliability estimates for the Chinese DACL are very similar in magnitude and direction to those obtained on the English version (Lubin, 1981). Although significant because of the large $N$, the correlations for test-retest reliability, as expected, are the lowest of any in the table. We used the state form of the DACL, and these should be sensitive to transient change. The previously mentioned correlations between the Chinese and English half lists also can be seen as evidence for the inter-language reliability of the DACL.

TABLE 1

Comparison of the Reliabilities of the Chinese and English Depression Adjective Check Lists

\begin{tabular}{ccc}
\hline \hline & & Version \\
Reliability & $(N=1307)$ & $\begin{array}{c}\text { English } \\
(N=856)\end{array}$ \\
\hline Alternate Form & & \\
rEF & $.88^{*}$ & $.89^{*}$ \\
rEG & $.87^{*}$ & $.86^{*}$ \\
rFG & $.89^{*}$ & $.87^{*}$ \\
Split-half & & \\
E & $.80^{*}$ & $.85^{*}$ \\
F & $.77^{*}$ & $.83^{*}$ \\
G & $.85^{*}$ & $.87^{*}$ \\
Test-retest (1 week $)$ & & $.19^{*}$ \\
E & $.24^{*}$ & $.24^{*}$ \\
F & $.19^{*}$ & $.22^{*}$ \\
G & $.23^{*}$ & \\
\hline
\end{tabular}

*Significant at .01.

\section{Validity}

The results of preliminary studies of the concurrent validity of the Chinese DACL can be seen in Table 2 . According to expectation, the relationship between the DACL and the 7-point self-rating scale produced the highest correlations for both the Chinese and the English versions. Both are measures of self-reported state depression.

Ko's Mental Health Questionnaire D Scale $(K o, 1972)$ is based upon the MMPI D Scale. In this regard, it is interesting to note that the correlation between Ko's Mental 
Health Questionnaire and the Chinese DACL is of a magnitude similar to those between the English DACL and the MMPI D Scale (Lubin, 1981).

From Table 2 we also can compare the magnitude and direction of the correlations between the Chinese and English versions of the DACL and the Bradburn Scale. For both the positive and negative subscales of the Bradburn Scale, the magnitude of the correlations across the two versions is quite similar. The negative correlations for the

TABLE 2

Comparison of the Concurrent Validity of the Chinese and English Depression Adjective Check Lists (Self-Rating Scale; Bradburn Scale; Ko's Mental Health Questionnaire)

\begin{tabular}{|c|c|c|c|c|}
\hline \multirow[b]{2}{*}{ DACL list } & \multicolumn{2}{|c|}{ Self-Rating Scale } & \multicolumn{2}{|c|}{$\begin{array}{l}\text { Ko's Mental Health Questionnaire } \\
\text { and/or MMPI-D Scale }\end{array}$} \\
\hline & $\begin{array}{c}\text { Chinese } \\
(N=1307)\end{array}$ & $\begin{array}{l}\text { English } \\
(N=113)\end{array}$ & $\begin{array}{c}\text { Chinese } \\
(N=1307)\end{array}$ & $\begin{array}{l}\text { English } \\
(N=80)\end{array}$ \\
\hline E & $.81^{*}$ & $.63 .^{*}$ & $.34^{*}$ & $.58^{*}$ \\
\hline $\mathrm{F}$ & $.74^{*}$ & $.58^{*}$ & $.31^{*}$ & $.57^{*}$ \\
\hline \multirow[t]{4}{*}{ G } & $.78^{*}$ & $.65^{*}$ & $.32^{*}$ & $.56^{*}$ \\
\hline & \multicolumn{4}{|c|}{ Bradburn Scale } \\
\hline & \multicolumn{2}{|c|}{ Positive Subscale } & \multicolumn{2}{|c|}{ Negative subscale } \\
\hline & $\begin{array}{l}\text { Chinese } \\
(N=1307)\end{array}$ & $\begin{array}{l}\text { English } \\
(N=113)\end{array}$ & $\begin{array}{l}\text { Chinese } \\
(N=1307)\end{array}$ & $\begin{array}{l}\text { English } \\
(N=113)\end{array}$ \\
\hline $\mathrm{E}$ & $-.36^{*}$ & $-.43^{*}$ & $.39^{*}$ & .31 \\
\hline $\mathrm{F}$ & $-.36^{*}$ & $-.42^{*}$ & .38 & .28 \\
\hline G & $-.39^{*}$ & $-.34^{*}$ & $.40^{*}$ & .30 \\
\hline
\end{tabular}

*Significant at .01.

TABLE 3

Comparison of the Concurrent Validity of the Chinese and English Depression Adjective Check Lists (Katz Symptom Scale and Self-Anchoring Striving Scale)

\begin{tabular}{lcccccc}
\hline \hline & \multicolumn{3}{c}{ Self-Anchoring Striving Scale } & \multicolumn{2}{c}{ Future } \\
DACL list & $\begin{array}{c}\text { Chinese } \\
(N=1307)\end{array}$ & $\begin{array}{c}\text { English } \\
(N=387)\end{array}$ & $\begin{array}{c}\text { Chinese } \\
(N=1307)\end{array}$ & $\begin{array}{c}\text { English } \\
(N=387)\end{array}$ & $\begin{array}{c}\text { Chinese } \\
(N=1307)\end{array}$ & $\begin{array}{c}\text { English } \\
(N=387)\end{array}$ \\
\hline $\mathrm{E}$ & $-.38^{*}$ & $-.45^{*}$ & $-.27^{*}$ & $-.28^{*}$ & .04 & .16 \\
$\mathrm{~F}$ & $-.39^{*}$ & $\mathrm{x}$ & $-.25^{*}$ & $\mathrm{x}$ & .03 & $\mathrm{x}$ \\
$\mathrm{G}$ & $-.29^{*}$ & $\mathrm{x}$ & $-.24^{*}$ & $\mathrm{x}$ & -.01 & $\mathrm{x}$ \\
& Katz Symptom Scale & & & & \\
& Chinese & English & & & & \\
$\mathrm{E}$ & $(N=1307)$ & $(N=387)$ & & & & \\
$\mathrm{F}$ & $.38^{*}$ & $.50^{*}$ & & & & \\
$\mathrm{G}$ & $.32^{*}$ & $\mathrm{x}$ & & & & \\
\hline
\end{tabular}

*Significant at .01 .

×Correlations not available. 
Positive Subscale and the positive correlations for the Negative Subscale are due to the fact that the scoring direction for the DACL and for the Bradburn Scale is reversed, i.e., high score on the DACL means increased depressive mood, whereas high score on the Bradburn Positive Subscale means increased positive mood.

A comparison of the concurrent validity of the Chinese and English DACL by means of correlations with the Katz Symptom Scale (Katz \& Lyerly, 1963), and the SelfAnchoring Striving Scale (Cantril, 1969) can be seen in Table 3. Again, for the Katz Symptom Scale, which measures psychophysiologic-psychosomatic symptoms, the level and direction of the correlations are similar.

The Self-Anchoring Striving Scale measures where a person perceives himself/herself in the past, the present, and the future. For both versions, the correlations for "past" and "present" are similar in direction and magnitude. The interesting finding here is that the correlation between the Chinese DACL and the "future" subscale of the Self-Anchoring Striving Scale is almost at the literal zero level. Further research will look into the possible role of a strong cognitive set to believe or to express that things will improve for each individual in the Chinese (Taiwanese) culture.

Additional differences between the two versions are shown in Table 4. The Chinese version produces the highest mean. These findings are at variance with the commonly held view that the Chinese generally do not express affective or even psychological complaints. They are much more likely to have somatic symptoms (Tseng, 1975; Yap, 1974). On the other hand, Cheung (1982) recently reported that the primacy of somatic complaints for the Chinese occurs when data are collected in medical situations, i.e., clinics, doctor's offices, etc. By contrast, her reanalysis of epidimologic data showed that urban Chinese scored significantly higher on the psychological subscale of the Langner Scale (Langner, 1962) than they did on the psychophysiological, physiological and ambiguous subscales (Crandell \& Dohrenwend, 1967). Our data collection situation was more similar to the situation described by Cheung (1982).

TABLE 4

Comparison of the Means and Standard Deviations for the Chinese and English Depression Adjective Check Lists

\begin{tabular}{lcccc}
\hline & \multicolumn{2}{c}{ Chinese } & \multicolumn{2}{c}{ English } \\
& $(N=1307)$ & \multicolumn{2}{c}{$(N=856)$} \\
DACL list & $M$ & $S D$ & $M$ & $S D$ \\
\hline E & 10.77 & 6.15 & 8.04 & 5.43 \\
F & 10.40 & 5.14 & 8.45 & 4.80 \\
G & 10.20 & 6.35 & 8.25 & 5.48 \\
\hline
\end{tabular}

The findings with regard to fidelity of the translation and the reliability and concurrent validity of the Chinese DACL indicate that this instrument is suitable for research use.

\section{REFERENCES}

Bradburn, N. M. (1969). The structure of psychological well-being. Chicago: Aldine.

Cantril, H. (1969). Patterns of human concerns. New Brunswick, NJ: Rutgers University.

Cheung, F. M. (1982). Psychological symptoms among Chinese in urban Hong Kong. Social Science and Medicine, 16, 1339-1344. 
Crandell, D. L., \& Dohrenwend, B. P. (1967). Some relations among psychiatric symptoms, organic illness, and social class. American Journal of Psychiatry, 123, 1527-1538.

KATZ, N. M., \& LyERLy, S. B. (1963). Methods for measuring adjustment and social behavior in the community: Rationale, description, discriminative validity and scale development. Psychological Reports, 13, 503-535.

Ko, Y. H. (1972). The study on the validity of the male and female scores of the Ko Mental Health Questionnaire. Psychological Testing, 19, 7-8.

LANGNER, T. S. (1962). A twenty-two item screening score of psychiatric symptoms indicating impairment. Journal of Health and Human Behavior, 3, 269-276.

LevitT, E. E., Lubin, B., \& Brooks, J. (1983). Depression: Concepts, controversies, and some new facts (2nd ed.). Hillsdale, NJ: Erlbaum.

Lomranz, J., Lubin, B., Eyal, N., \& Medini, G. (1981). A Hebrew version of the Depression Adjective Check Lists. Journal of Personality Assessment, 45, 380-384.

LuBIN, B., (1981). Depression Adjective Check Lists: Manual (2nd ed.). San Diego, CA: EdITS.

Lubin, B., Caplan, M., \& Collins, J. F. (1980). Additional evidence fot the comparability of Set 2 (E, F, and $G$ ) of the Depression Adjective Check Lists. Psychological Reports, 46, 849-850.

Lubin, B., DUpre, V. A., \& Lubin, A. W. (1967). Comparability and sensitivity of Set 2 (Lists E, F, and G) of the Depression Adjective Check Lists. Psychological Reports, 20, 756-758.

Lubin, B., \& Himelstein, P. (1976). Reliability of the Depression Adjective Check Lists. Perceptual and Motor Skills, 3, 1037-1038.

Lubin, B., Millham, J., \& Parades, F. (1980). Spanish language versions of the Depression Adjective Check Lists: Reliability and validity. Hispanic Journal of Behavioral Sciences, 2, $51-57$

Lubin, B., Schoenfeld, L. S., Rinck, C., \& Millham, J. (1980). Reliability and validity of the Spanish Depression Adjective Check Lists: Psychiatric patients and normals. Interamerican Journal of Psychology, 13, 53-55.

TSENG, W. S. (1975). The nature of somatic complaints among psychiatric patients: The Chinese case. Comprehensive Psychiatry, 16, 237-245.

YAP, P. M. (1974). Comparative psychiatry. Toronto: University of Toronto Press. 